\title{
Research on Corrosion Damage and Bearing Characteristics of Bridge Pile Foundation Concrete under a Dry-Wet-Freeze-Thaw Cycle
}

\author{
Zhongju Feng $\mathbb{D}^{1},{ }^{1}$ Jianwei Huo $\mathbb{D}^{1},{ }^{1}$ Haibo Hu $\mathbb{D}^{2},{ }^{2}$ Ruixin Zhao, ${ }^{1}$ Fuchun Wang, \\ Guan Jiang, ${ }^{1}$ Xianhua Yao $\left[1,{ }^{3}\right.$ Tie $\mathrm{Li}^{1}{ }^{1}$ and Zhenyu Song ${ }^{1}$ \\ ${ }^{1}$ School of Highway, Chang'an University, Xi'an, Shaanxi 710064, China \\ ${ }^{2}$ Research Center of Coastal and Urban Geotechnical Engineering, Zhejiang University, Hangzhou, Zhejiang 310058, China \\ ${ }^{3}$ School of Civil Engineering and Communication, North China University of Water Resources and Electric Power, Zhengzhou, \\ Henan 450046, China
}

Correspondence should be addressed to Jianwei Huo; huojianwei@chd.edu.cn

Received 7 August 2020; Revised 8 December 2020; Accepted 28 December 2020; Published 19 January 2021

Academic Editor: Bingxiang Yuan

Copyright $\odot 2021$ Zhongju Feng et al. This is an open access article distributed under the Creative Commons Attribution License, which permits unrestricted use, distribution, and reproduction in any medium, provided the original work is properly cited.

This study investigated the corrosion damage and bearing characteristics of bridge pile foundations under a dry-wet-freeze-thaw cycle of composite salt in an alpine salt marsh area using an in situ test, laboratory test, and numerical simulations. The in situ test showed that the dry-wet-freeze-thaw cycle has little effect on the quality of the concrete specimens and rebar. The area of the rebar at a depth of $0.25 \mathrm{~m}$ had the highest corrosion rate of $91 \%$. The application of epoxy resin on the surface improved erosion resistance. After one year of outdoor dry-wet-freeze-thaw cycle test, due to the interaction of compound salts, the quality of specimens is reduced under the denudation of chloride ions, while the mass of specimens is increased by the corrosion products formed under the joint action of carbonate and sulfate, resulting in less obvious change of specimen quality, the antierosion coefficient of the specimens decreased, the maximum loss rate of compressive strength was $38.2 \%$, and the pile foundation began to deteriorate. The laboratory test showed that expansive substances, such as Friedel salt, appeared in the concrete specimens of pile foundation during 225 cycles of dry-wet-freeze-thaw cycles, the relative dynamic elastic modulus was reduced by $60.9 \%$, the antierosion coefficient was reduced to 0.51 , and the compressive strength loss rate was $65.9 \%$. As such, the pile foundation was seriously damaged. The numerical simulation shows that, with an increase of the peeling thickness and the corrosion depth, the bearing capacity of the pile foundation will gradually decrease after 8 years. Without maintenance, the bearing capacity of a pile foundation will decrease by $34.45 \%$ in the $20^{\text {th }}$ year.

\section{Introduction}

With the promotion of the Western Development Strategy in China, "development driven by traffic" has become an important part of construction in Qinghai Province. However, terrain conditions are complicated. During the construction of roads and bridges, many problems are encountered. Among them, corrosion damage and bearing characteristics of pile foundations is a concern [1-5]. Feng et al. [1-3] analyzed the relative dynamic elastic modulus and compressive strength of pile foundation concrete in an in situ test and predicted the life of the pile foundation without maintenance. Murad et al. $[6,7]$ used the in situ tests to study the bearing characteristics of a pile foundation of the I-10 double-span bridge in Louisiana. According to the fitting curve and mathematical derivation, it was considered that there was no group effect in the derived p-y curve. Pilehvar et al. [8-11] studied the mechanical properties and durability of pile foundation concrete after replacing cement with fly ash under the conditions of freeze-thaw cycles in laboratory model tests. Ghazy et al. [12-14] studied the mechanical properties and durability of concrete specimens under the conditions of 
indoor freeze-thaw cycles, as well as the microscopic changes of specimens using scanning electron microscopy.

Other researchers have focused on pile foundations under special circumstances. Shi et al. $[15,16]$ studied the axial loadbearing characteristics of cone-pillar pile foundations in noncohesive soil under freeze-thaw cycles by laboratory tests and proposed an appropriate design scheme. Feng et al. [1, 17] studied the vertical load-bearing characteristics of concretefilled steel, tube-reinforced concrete piles in a loess area based on a centrifugal model test. Dong et al. [18] discussed liquefaction identification of saturated silty sand of bridge pile foundations under simulated earthquake conditions using a large-scale shaking table test of a laminated shear model box. Ali et al. $[19,20]$ studied the bearing characteristics of bridge pile foundations in expansive soil, proposing a corresponding probability model; they verified the feasibility of the models based on practical cases. Yan et al. [21] studied the mechanical properties and deformation characteristics of pile group foundations nested in inclined weak interlayers with a centrifugal model test. Feng et al. [22] studied the distance effect and bearing characteristics of pile foundation under faultpile-rock-soil interaction.

Some researchers have used numerical simulation to study the mechanical properties of pile foundations. Yao et al. $[23,24]$ studied the vertical bearing characteristics of bridge pile foundations in salt marshes with different spalling thicknesses and corrosion depths by manipulating the pile diameter and pile length in numerical simulations. Weyers [25] studied the service life of reinforced concrete in a chlorine-containing environment by numerical simulation and established a corresponding prediction model. Lang et al. [26, 27] studied the bearing characteristics of four different types of marine bridge pile foundations by a numerical simulation model. Feng et al. [28] studied the bearing characteristics of bridge pile foundations under the condition of liquefaction of foundation soil by improving a numerical simulation calculation method.

Predecessors used different methods such as the in situ test, laboratory test, and numerical simulations to study the mechanical properties of bridge pile foundations under dry-wet or freeze-thaw cycles, but the research methods and research environmental conditions are relatively simple, and few people use these three methods to study the bearing characteristics and corrosion damage of pile foundation under the dry-wet-freezethaw cycles. In addition, many researchers have studied the mechanical properties of pile foundations under special conditions such as cohesive soil, loess, expansive soil, weak interlayers, and earthquakes, but few have studied the bearing characteristics and corrosion damage of pile foundation in the special environment of alpine salt marsh area. This paper explores this dynamic in an alpine salt marsh area with the in situ test, laboratory test, and numerical simulations. Based on the results, engineering suggestions are given to provide a reference for similar projects.

1.1. Project Overview. Dexiang Expressway is an important traffic route from Qinghai Province to the hinterland of Haixi Prefecture with a total length of $165 \mathrm{~km}$. Affected by regional climate, salt marshes are widely distributed along the route, as shown in Figures 1(a) and 1(b). Due to the high wind and low rain, as well as the large temperature differences between day and night, it is affected by a strong drywet-freeze-thaw cycle, resulting in many structural problems, as shown in Figure 1. The salt water-influenced section of the main line of the Dexiang Expressway is about $22.7 \mathrm{~km}$. The makeup of the road sections is shown in Figure 2.

\section{Materials and Methods}

\subsection{In Situ Test}

2.1.1. Materials. To study corrosion characteristics of representative pile foundations, $150 \mathrm{~mm} \times 150 \mathrm{~mm} \times 150 \mathrm{~mm}$ pile foundation concrete block specimens were fabricated and buried in water, ground, $0.25 \mathrm{~m}$ underground, and $1.25 \mathrm{~m}$ underground. The mixing ratio of the specimens is shown in Table 1, and location distribution is shown in Figure 3. The burial ages were 3, 9, and 12 months.

\subsubsection{Test Index}

(1) Quality. The quality of the specimen was weighed using an electronic balance with an accuracy of $0.1 \mathrm{~g}$, which can reflect the quality change of the specimen before and after corrosion.

(2) Antierosion Coefficient. The antierosion coefficient is used to describe the degree of corrosion resistance of the specimen, and it is calculated as follows:

$$
K_{c}=\frac{R_{c}}{R_{s}},
$$

where $K_{c}$ is the antierosion coefficient of the specimen; $R_{c}$ is the compressive strength of specimen immersed in erosion solution, $\mathrm{MPa}$; and $R_{s}$ is the compressive strength of specimens immersed in water at the same age, MPa.

(3) Compressive Strength. After the specimens reached the specified ages, they were removed and weighed (the specimens in water were washed and dried before weighing), and the uniaxial compression resistance of the specimens was performed on the electrohydraulic servo universal testing machine (pressure $2000 \mathrm{kN}$ ) of North China University of Water Resources and Electric Power, Zhengzhou, China.

(4) Corrosion Rate. The bridge pile foundation needs to be reinforced during the construction process. To simulate an actual situation, three kinds of rebar were used in the construction process: $\varphi 12 \mathrm{~mm}, \varphi 25 \mathrm{~mm}$ threaded rebar, and one with the surface coated with epoxy resin on $\varphi 25 \mathrm{~mm}$ threaded rebar $\left(\varphi 25^{\prime}\right)$. When preembedded, the rebar was first allowed to rust. After reaching the specified ages, they were removed; see Figure 4.

After the rebars were taken out, the area corrosion rate and quality corrosion rate were measured. Before measurement, a full cleaning was carried out to remove the 


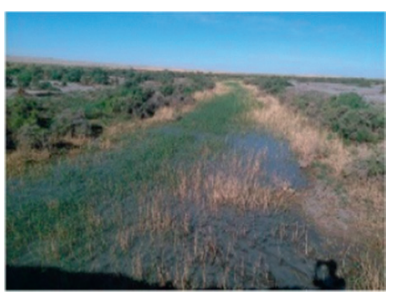

(a)

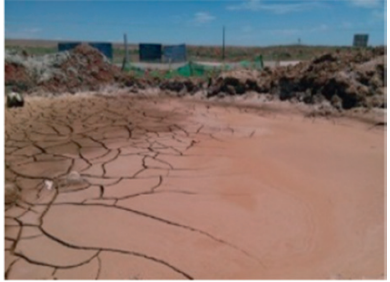

(b)

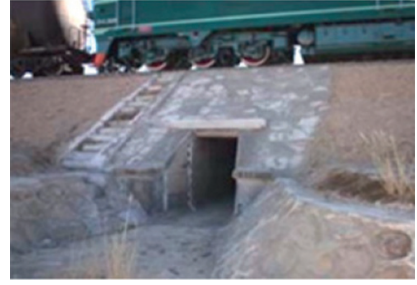

(c)

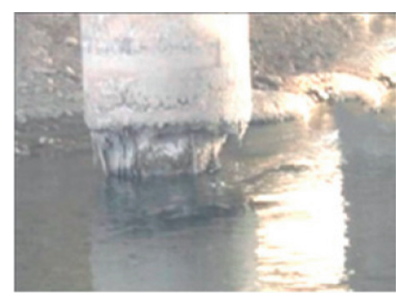

(d)

Figure 1: Overview along the route. (a) Salt marsh. (b) Wet and dry effect. (c) Abandoned culvert. (d) Exposed rebar.

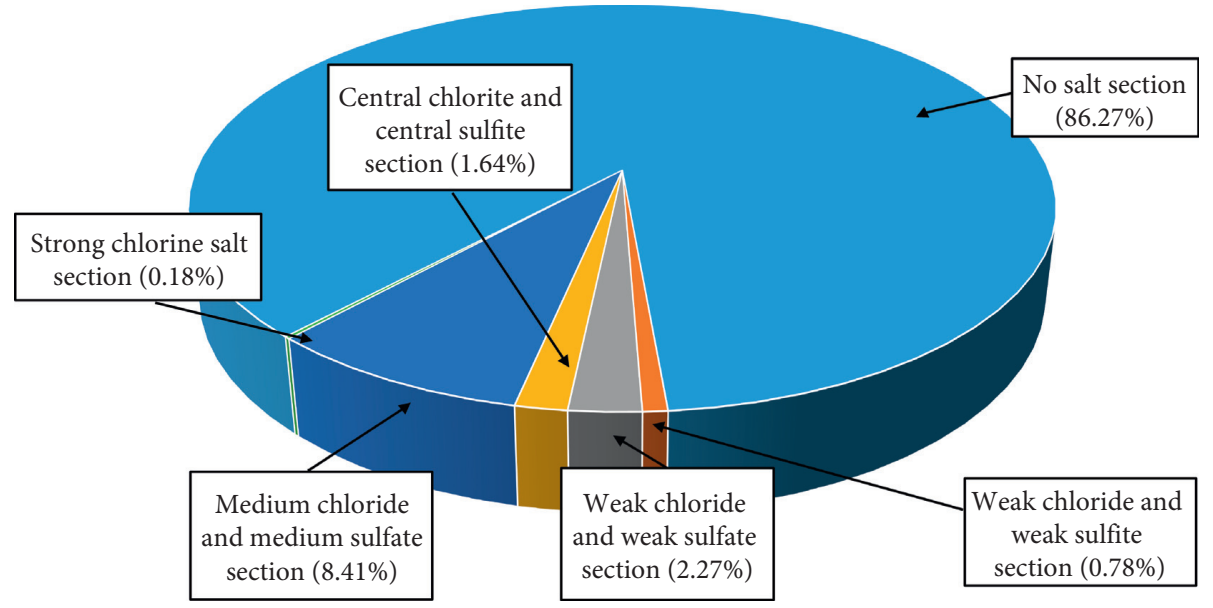

FIGURE 2: Sections influenced by salt on the Dexiang Expressway.

TABLE 1: C30 concrete ratio content $\left(\mathrm{kg} / \mathrm{m}^{3}\right)$.

\begin{tabular}{lccccc}
\hline Matching & Cement & Sand & Gravel & Water & Water reducer \\
\hline Content & 436 & 767 & 1103 & 170 & 5.23 \\
\hline
\end{tabular}

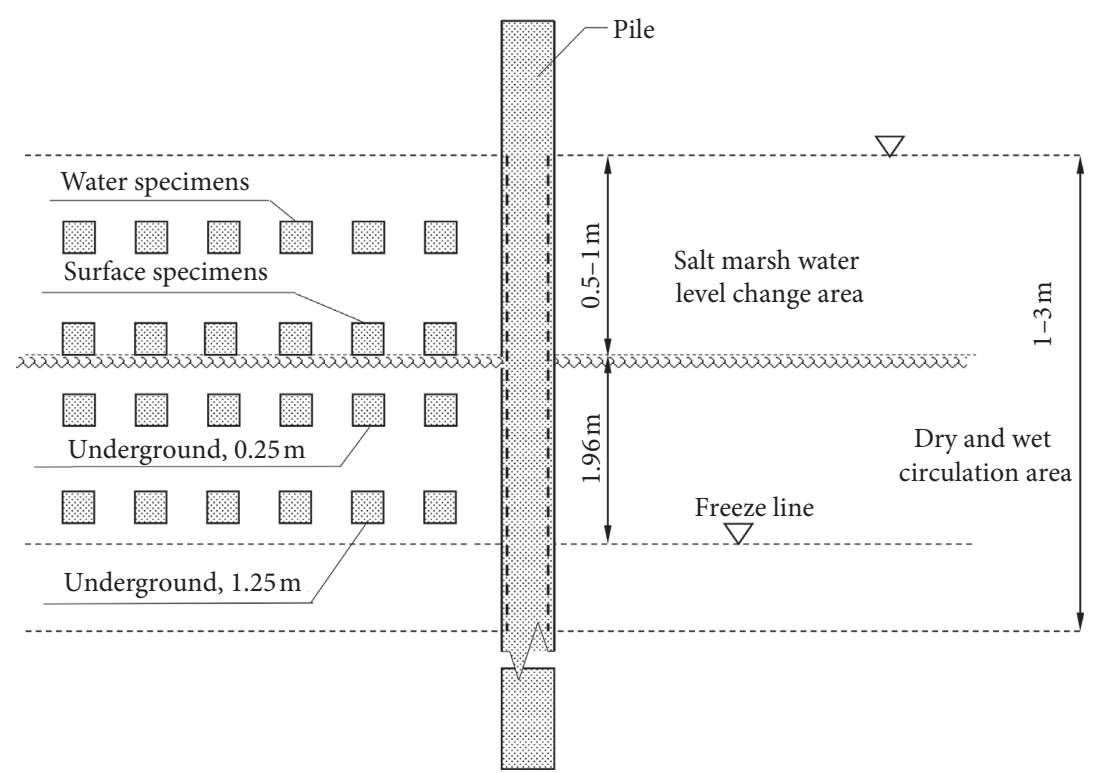

FIGURE 3: Location distribution of concrete specimens of pile foundation. 


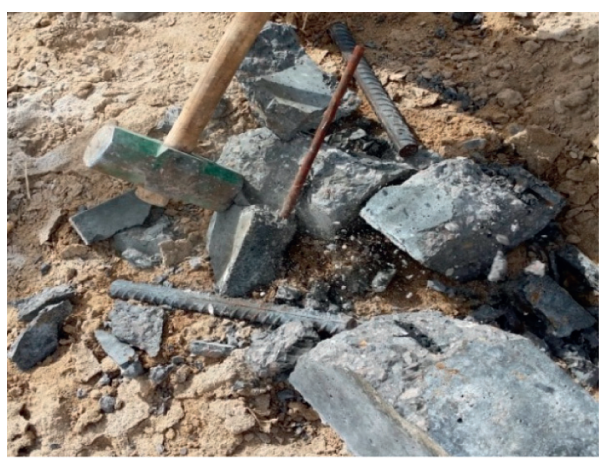

(a)

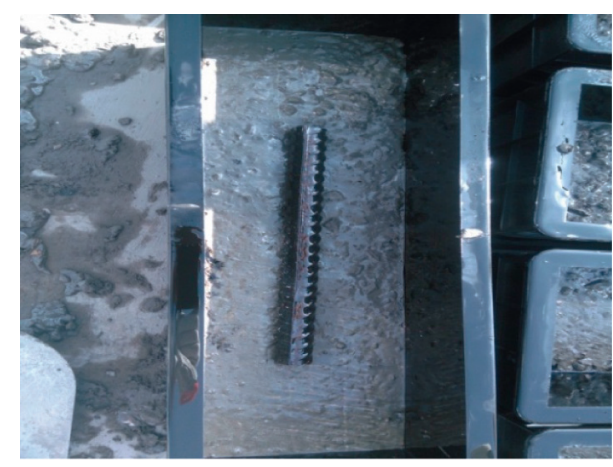

(b)

Figure 4: Take out rebar specimens onsite.

concrete on the surface of the rebar. The calculation methods are given as equations (2) and (3):

Area corrosion rate:

$$
\delta=\frac{S_{0}-S_{1}}{S_{0}}
$$

Quality corrosion rate:

$$
\lambda=\frac{m_{0}-m_{1}}{m_{0}}
$$

where $S_{0}$ is the surface area excluding both ends of the rebar; $S_{1}$ is the corrosion area of the rebar surface; and $m_{0}$ and $m_{1}$ are the masses before and after the corrosion of the rebar. When calculating area corrosion, put the rebar on the graph paper and draw the corrosion area, so as to calculate the corrosion area of the rebar. The area corrosion rate calculation is shown in Figure 5.

2.2. Laboratory Test. The in situ test could not be used to simulate the long-term performance of the pile foundations after corrosion. Therefore, indoor accelerated tests were used to examine mechanical properties and microscopic mechanisms of pile foundations with corrosion.

2.2.1. Materials. The test employed different materials (carbonate, sulfate, and chloride) and climates (dry-wet and freeze-thaw cycle) to simulate the actual working conditions of the bridge pile foundation concrete under salt dry-wetfreeze-thaw cycles. According to the onsite investigation, the content of each ion in the compound salt solution is shown in Tables 2 and 3.

Indoor and in situ tests used the same proportion of concrete specimens. They were divided into two types: one was a block with side lengths of $100 \mathrm{~mm}$ used to measure the mass and relative dynamic elastic modulus of the specimen before and after the test. The other was a prism $(100 \mathrm{~mm} \times 100 \mathrm{~mm} \times 400 \mathrm{~mm})$ used to measure the compressive strength and microstructure of the specimens. To better simulate the service environment of the pile foundation concrete, the formed specimens were left for 24 hours, the molds were removed, they were allowed to cure to the specified ages, and then the tests were carried out.

2.2.2. Test Procedure. After curing the specimens for 24 days, they were immersed in the compound salt solution prepared in advance (4 days prior). After removing the specimens and freezing them at $-15 \pm 2^{\circ} \mathrm{C}$ for 2 hours, they were thawed at $6 \pm 2^{\circ} \mathrm{C}$ for 2 hours. This operation was a freeze-thaw cycle: samples were placed in an oven at $80 \pm 5^{\circ} \mathrm{C}$ for 8 hours, then cooled for 1 hour, and soaked for 15 hours. This operation was a dry-wet cycle $[2,3,23]$. The quality and dynamic elastic modulus of the specimens were measured 25 times. Representative specimens were selected for the compressive strength test and scanning electron microscope (SEM) test and the chemical elements were analyzed by EDS as shown in Figure 6. Three sets of specimens are selected for research each time.

\subsubsection{Test Index}

(1) Quality loss rate:

$$
\Delta W_{n}=\frac{G_{0}-G_{n}}{G_{0}} \times 100 \%,
$$

where $\Delta W_{n}$ is the quality loss rate of the specimen; $G_{0}$ is the initial mass of the specimen, $g$; and $G_{n}$ is quality of specimen after a certain number of cycles, g.

(2) Relative dynamic elastic modulus:

$$
E_{r}=\left(\frac{f_{n}}{f_{0}}\right)^{2}
$$

where $E_{r}$ is relative dynamic elastic modulus; $f_{0}$ is the initial frequency of the specimen measured with a dynamic elastic modulus tester; and $f_{n}$ is the frequency of specimen after $N$ test cycles.

(3) Compressive strength:

In order to make the test results more accurate, three specimens were measured by an electrohydraulic 


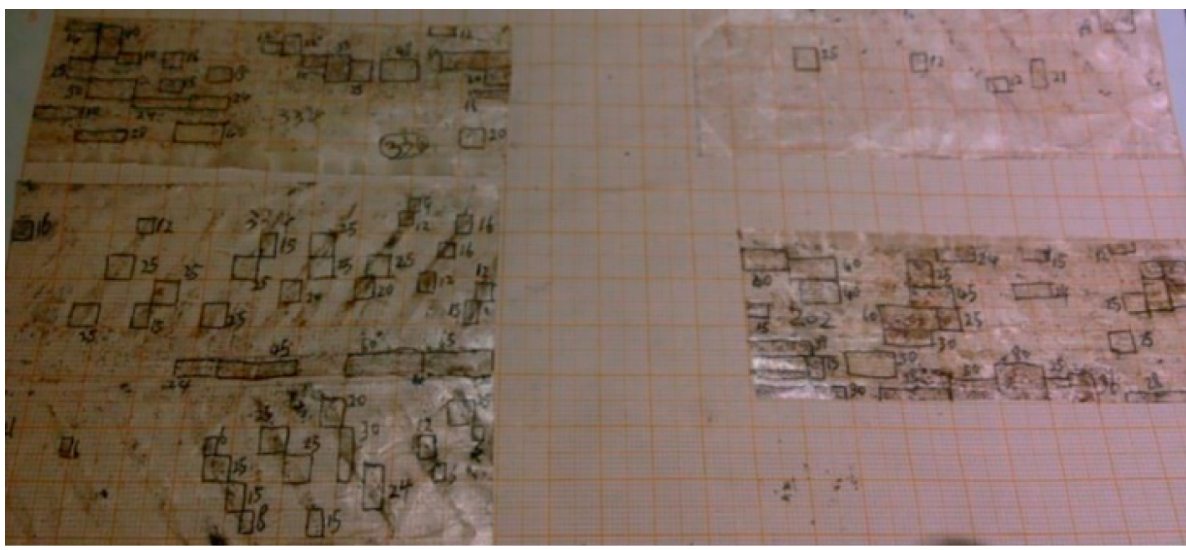

FIgURE 5: Area corrosion rate calculation.

TABle 2: Content of ions in the water.

\begin{tabular}{lcccc}
\hline \multirow{2}{*}{ Types of water } & \multicolumn{2}{c}{ Soluble salt content $(\mathrm{mg} / \mathrm{L})$} & $\mathrm{Cl}^{-}$ & $\mathrm{pH}$ value \\
& $\mathrm{SO}_{4}{ }^{2-}$ & $\mathrm{HCO}^{3-}$ & 392.2 & 18818.8 \\
Ground water & 2400.0 & 454.7 & 8498.7 & 7.0 \\
Surface water & 720.6 & 7.0 \\
\hline
\end{tabular}

TABLE 3: Content of each salt in complex salt.

\begin{tabular}{lcccc}
\hline \multirow{2}{*}{ Erosion solution } & & Types of salt $(\mathrm{g} / \mathrm{L})$ & Solution concentration (\%) \\
& $\mathrm{Na}_{2} \mathrm{SO}_{4}$ & $\mathrm{NaCl}$ & $\mathrm{NaHCO}_{3}$ & 3.4 \\
\hline Content & 3.55 & 31.01 & 0.54 & \\
\hline
\end{tabular}

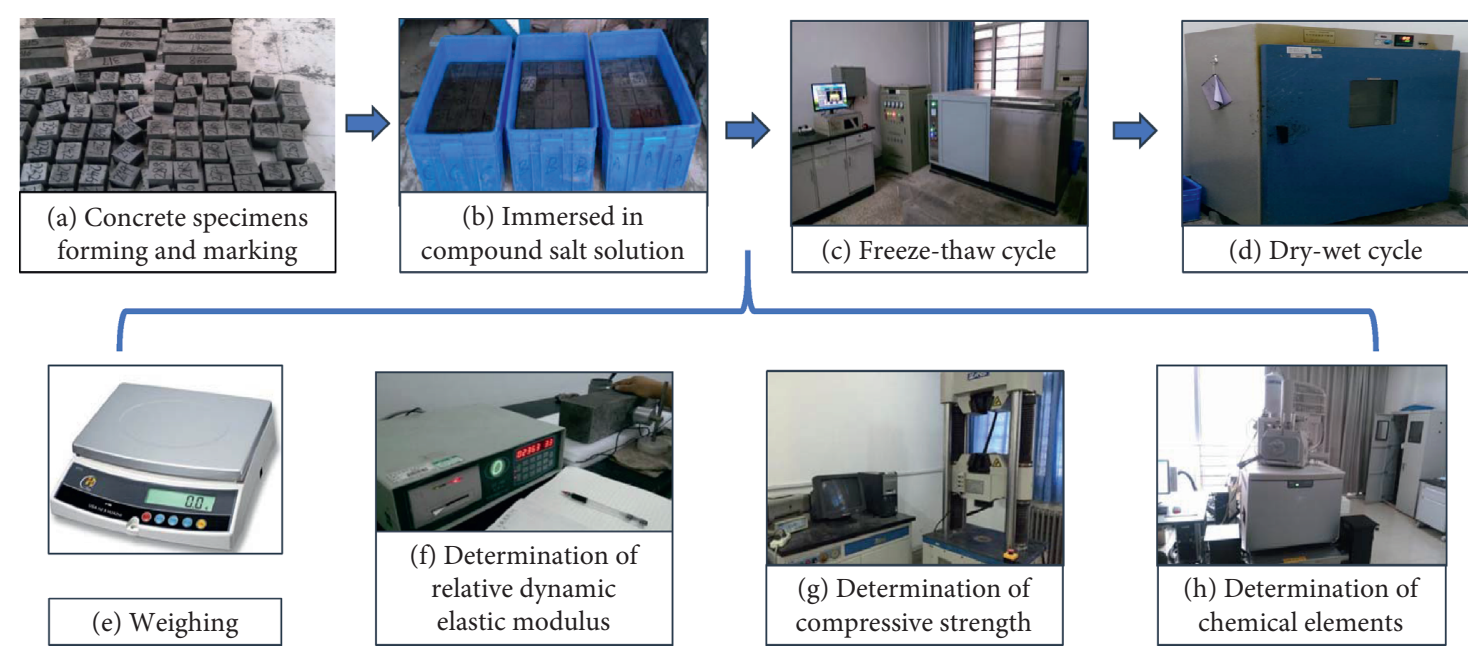

FIGURE 6: Dry-wet-freeze-thaw cycle test process.

servo universal testing machine, and the arithmetic mean of three was obtained. If the difference between the intermediate value and the maximum and minimum values did not exceed $15 \%$, the average value was taken as the compressive strength. If the difference between the intermediate value and the maximum and minimum value exceeded $15 \%$, the intermediate value was taken as the measured value. If both differences are greater than $15 \%$, the data were not used.

(4) Antierosion coefficient:

The antierosion coefficient of the specimen was calculated according to equation (1). 


\subsection{Numerical Simulation}

2.3.1. Model Framework. Based on previous research $[23,24,29]$, the peeling thickness and corrosion depth reflect the severity of the corrosion of a bridge pile foundation. According to the surveys of corrosion of the substructure of bridge pile foundations in the Qinghai area, the corrosion depth is concentrated at $8 \mathrm{~m}$ below the ground surface and the peeling rate of the pile concrete is about $3 \mathrm{~cm} / 4$ years. So, the reduction in pile diameter is set to $3 \mathrm{~cm}$ per 4 years, and the reduction in corrosion depth is set to $1.6 \mathrm{~m}$ per 4 years in the model. The peeling thickness and corrosion depth corresponding to different times are shown in Table 4.

2.3.2. Model Establishment. Marc finite element software was used to simulate the bearing characteristics and corrosion damage of bridge pile foundations for alpine salt marsh regions. The pile diameter was set as $1.8 \mathrm{~m}$, the pile length as $40 \mathrm{~m}$, the model boundary as 8 times the pile diameter [30], and the pile subsoil thickness as $20 \mathrm{~m}$. The geometric model schematic is shown in Figure 7.

The foundation soil is regarded as an ideal elastoplastic model, and the spalled area and pile foundation concrete materials are as well. The Mohr-Coulomb yield criterion can be used to better simulate the interaction between piles and soil. In the modeling process, it was assumed [31] that each rock and soil body were homogeneous, isotropic, and continuous.

2.3.3. Parameter Selection. Wu et al. [32] converted the number of onsite dry-wet-freeze-thaw cycles to the number of indoor dry-wet-freeze-thaw cycles and believed that Qinghai Province would experience an average of 110 dry-wet-freezethaw cycles per year, equivalent to about 11 indoor dry-wetfreeze-thaw cycles. According to the laboratory test, the relative dynamic elastic modulus of the specimens after 225 cycles was reduced by $60.9 \%$ at which time it is considered that the pile foundation function fails [33]. In the numerical simulation calculation, the corrosion depth of the pile foundation is simulated based on the attenuation amplitude of the relative dynamic elastic modulus as measured by the dry-wet-freeze-thaw cycle in the laboratory test, and the peeling thickness of the pile foundation is simulated by changing the pile diameter. The model parameters corresponding to different peeling thicknesses and corrosion depths are shown in Table 5.

2.3.4. Method Analysis. When the model was established, the pile diameter was set to $1.8 \mathrm{~m}$, and the pile length was $40 \mathrm{~m}$ for the first time. The width of the outer grid of the pile foundation is set to $3 \mathrm{~cm}$ for each layer, the 5 layers are $15 \mathrm{~cm}$ in total, and the remaining internal grids are equally divided. Eight metres down from the pile-soil boundary, set as a corrosion depth zone, the grid is divided into 5 parts, each part is $1.6 \mathrm{~m}$ high, and the rest of the internal grids are equally divided. Each time the model is calculated, the study of the thickness of the pile
TABLE 4: Spalling thickness and corrosion depth at different times.

\begin{tabular}{lcccccc}
\hline Years & 0 & 4 & 8 & 12 & 16 & 20 \\
\hline Peeling thickness $(\mathrm{cm})$ & 0 & 3 & 6 & 9 & 12 & 15 \\
Corrosion depth $(\mathrm{m})$ & 0 & 1.6 & 3.2 & 4.8 & 6.4 & 8 \\
\hline
\end{tabular}

foundation spalling is achieved by changing the parameters of the outer grid of the pile diameter from the outside to the inside (each change is $3 \mathrm{~cm}$ ); the change of the corrosion depth of the pile foundation is realized by changing the length of the corrosion zone from top to bottom (each change is $1.6 \mathrm{~m}$ ); and after each change is completed, the P-S load-settlement curve is extracted, and the load corresponding to a settlement of $40 \mathrm{~mm}$ is the corresponding bearing capacity of the pile foundation $[24,28]$. The model calculation diagram is shown in Figure 8.

\section{Results}

\subsection{Results of In Situ Test}

3.1.1. Quality Changes. The quality changes of concrete specimens with different depths of pile foundations are shown in Figure 9. With an increase in the corrosion time, the quality change increased or decreased under the four embedding conditions, but the overall variation did not exceed $2 \%$. The quality of the specimens in the chloride ion ablation was reduced, and the corrosion products generated under the combined action of carbonate and sulfate increased the quality of the specimens, resulting in an insignificant change in the quality of the specimens under the interaction of the compound salts. The main equation is as follows:

$$
\begin{array}{r}
\mathrm{CaSiO}_{3}+2 \mathrm{Cl}^{-} \longrightarrow \mathrm{CaCl}_{2}+\mathrm{SiO}_{3}^{2-} \\
\mathrm{Ca}^{2-}+\mathrm{SO}_{4}^{2-} \longrightarrow \mathrm{CaSO}_{4} \downarrow \\
\mathrm{Ca}^{2-}+\mathrm{CO}_{3}^{2-} \longrightarrow \mathrm{CaCO}_{3} \downarrow \\
\mathrm{Fe}^{3+}+3 \mathrm{HCO}_{3}^{-} \longrightarrow \mathrm{Fe}(\mathrm{OH})_{3} \downarrow+\mathrm{CO}_{2} \uparrow \\
\mathrm{Al}^{3+}+3 \mathrm{HCO}_{3}^{-} \longrightarrow \mathrm{Fe}(\mathrm{OH})_{3} \downarrow+\mathrm{CO}_{2} \uparrow
\end{array}
$$

3.1.2. Antierosion Coefficient. The change of the antierosion coefficient of concrete specimens with different depths of pile foundation is shown in Figure 10, and the regression equations and correlation coefficients corresponding to the antierosion coefficients are shown in Table 6 . From the water to $1.25 \mathrm{~m}$ underground, the correlation coefficient of each regression equation increases. The antierosion coefficient of the pile concrete specimens at the corresponding time was obtained, which provides a basis for evaluating the durability of the specimen. With the increase in time, the antierosion coefficient at $0.25 \mathrm{~m}$ in water, surface, and underground increases and then decreases, indicating that the performance of specimens has begun to deteriorate. With less 


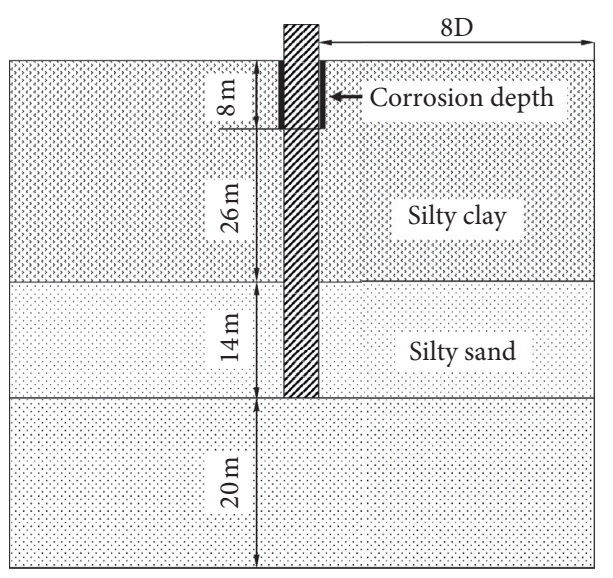

(a)

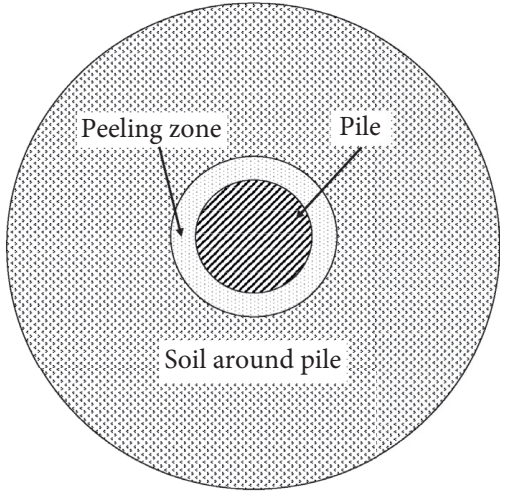

(b)

Figure 7: Geometric model schematic. (a) Geometric model elevation. (b) Cross section of pile corrosion.

TABLE 5: Model material parameters.

\begin{tabular}{lcccccc}
\hline \multicolumn{2}{c}{ Material name } & $\begin{array}{c}\text { Bulk density } \\
\gamma\left(\mathrm{kN} / \mathrm{m}^{3}\right)\end{array}$ & $\begin{array}{c}\text { Cohesion } \\
c(\mathrm{kPa})\end{array}$ & $\begin{array}{c}\text { Elastic modulus } \\
E(\mathrm{MPa})\end{array}$ & $\begin{array}{c}\text { Poisson's ratio } \\
\mu\end{array}$ & $\begin{array}{c}\text { Internal friction angle } \\
\varphi\left({ }^{\circ}\right)\end{array}$ \\
\hline Pile & - & 25.0 & - & $3.0 \times 10^{4}$ & 0.20 & - \\
Silty sand & - & 18.4 & 10.8 & 12.5 & 0.33 & 30 \\
Silty clay & - & 18.3 & 20 & 5.6 & 0.30 & 20 \\
Peeling $3.0 \mathrm{~cm}$ & Corrosion $1.6 \mathrm{~m}$ & 25.0 & - & $2.78 \times 10^{4}$ & 0.20 & - \\
Peeling $6.0 \mathrm{~cm}$ & Corrosion 3.2 m & 25.0 & - & $2.65 \times 10^{4}$ & 0.20 & - \\
Peeling $9.0 \mathrm{~cm}$ & Corrosion 4.8 m & 25.0 & - & $2.32 \times 10^{4}$ & 0.20 & - \\
Peeling $12 \mathrm{~cm}$ & Corrosion 6.4 m & 25.0 & - & $2.06 \times 10^{4}$ & 0.20 & - \\
Peeling $15 \mathrm{~cm}$ & Corrosion $8.0 \mathrm{~m}$ & 25.0 & - & $1.84 \times 10^{4}$ & 0.20 & - \\
\hline
\end{tabular}

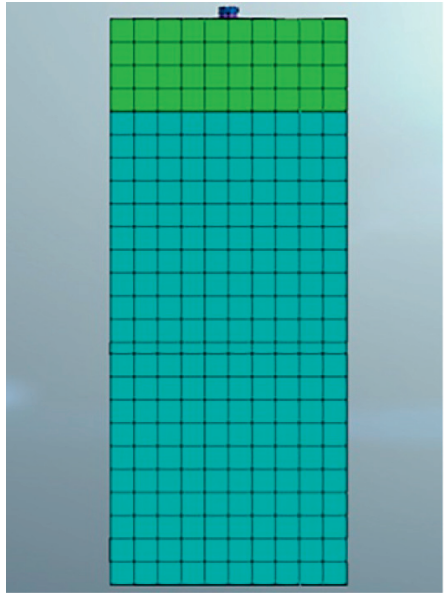

(a)

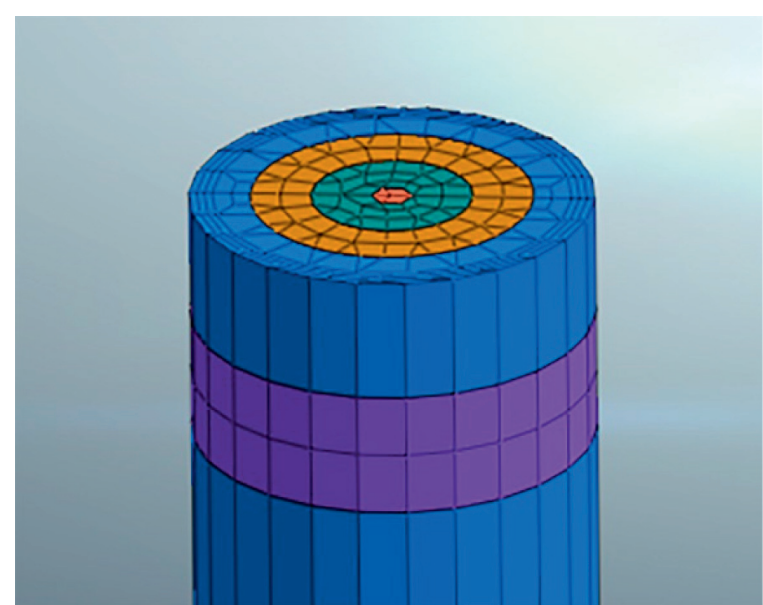

(b)

Figure 8: Numerical simulation model calculation diagram. (a) Overall schematic of the model. (b) Partial enlargement of the model.

depth, the hydration of earlier specimens is slow and the antierosion coefficient increases over time.

3.1.3. Compressive Strength Loss Rate. The change of compressive strength loss rate of concrete specimens with different depths of pile foundations is shown in Figure 11.
With the increase of age, the loss rate increased with a maximum loss of $38.2 \%$. For a given age, as the depth increases, the loss rate increases first, then decreases, and finally increases. This is because the one specimen is immersed in water, and the compressive strength of the specimens underground is higher due to the slow hydration. 


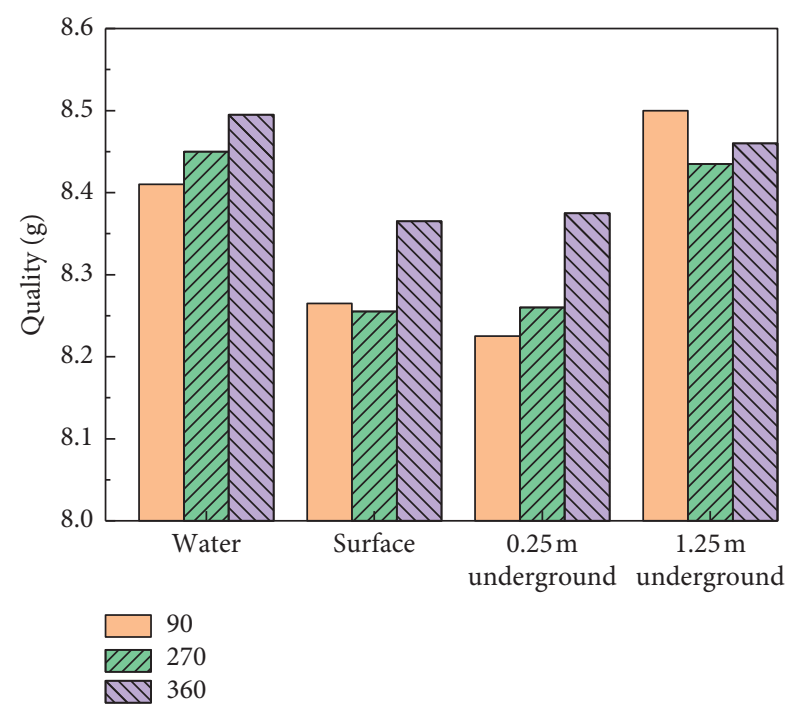

FIGURE 9: Quality change of pile foundation concrete specimens.

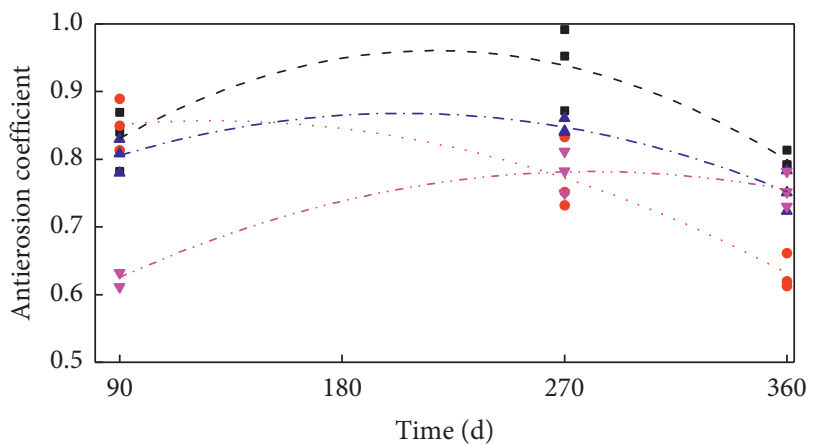

- Measured value in water

- Measured value at $0.25 \mathrm{~m}$ underground

- Measured value in surface

$\checkmark$ Measured value at $1.25 \mathrm{~m}$ underground

- - - Regression curve in water

-... Regression curve at $0.25 \mathrm{~m}$ underground

Regression curve in surface

Regression curve at $1.25 \mathrm{~m}$ underground

Figure 10: Change of the antierosion coefficient of pile foundation concrete specimen.

TABLE 6: Regression equations of the antierosion coefficient at different depths.

\begin{tabular}{lc}
\hline Location & Regression equation and $R^{2}$ \\
\hline Water & $y=-8 \times 10^{-6} x^{2}+0.034 x+0.59, R^{2}=0.71$ \\
Surface & $y=-4 \times 10^{-6} x^{2}+0.001 x+0.792, R^{2}=0.82$ \\
$0.25 \mathrm{~m}$ underground & $y=-5 \times 10^{-6} x^{2}+0.0021 x+0.656, R^{2}=0.88$ \\
$1.25 \mathrm{~m}$ underground & $y=4 \times 10^{-6} x^{2}+0.0025 x+0.4269, R^{2}=0.93$ \\
\hline
\end{tabular}

\subsubsection{Corrosion Rate of Rebar}

(1) Area Corrosion Rate. See Table 7 for the corrosion rate of different types of rebar at different depths. Taking $\varphi 25 \mathrm{~mm}$ as an example, the corrosion rate from water to $1.25 \mathrm{~m}$ underground is $76 \%, 91 \%, 66 \%$, and $65 \%$. The corrosion rate of

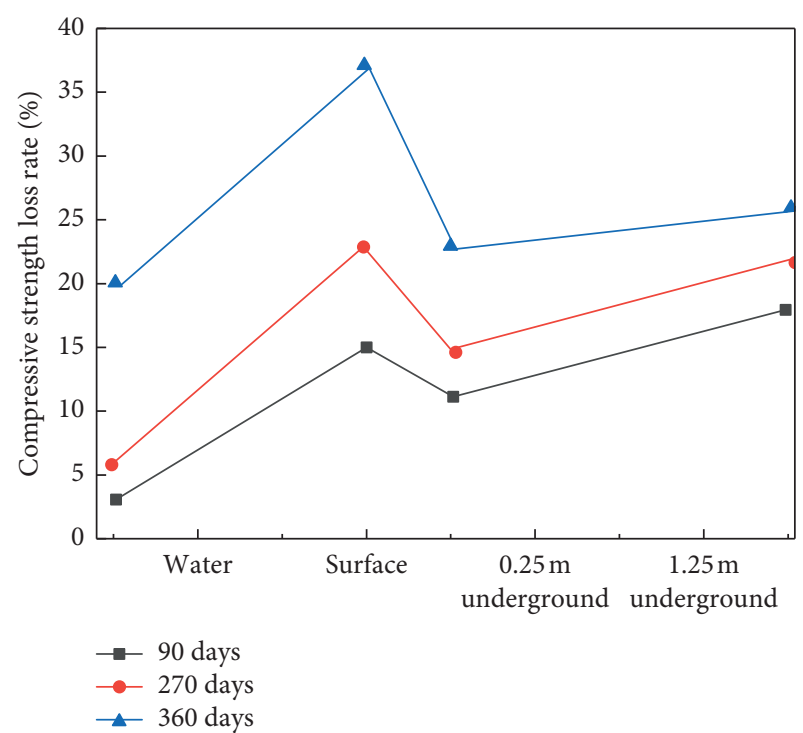

FIgURE 11: Change in the compressive strength loss rate of pile foundation concrete specimens.

the rebar area increases first and then decreases from surface to depth. It can be seen from Table 7 that, in the compound salt environment, the $\varphi 25^{\prime}$ rebar coated with epoxy resin exhibits a good rust inhibition. After 360 days of testing, the surface of the rebar has no corrosion, while the rebar without epoxy resin has large corrosion areas as shown in Figure 12.

(2) Quality Corrosion Rate. The rebars with the largest areas of corrosion were selected to measure the quality corrosion rate (Table 8). Although the corrosion rate of the rebar area was large, the mass loss was small, and the mass loss rate is less than $0.5 \%$, which has little effect on the mechanical properties of the rebar.

According to in situ test analysis, after one year of drywet-freeze-thaw cycles, the overall performance of the concrete specimens has relatively low changes. The quality of the reinforced concrete specimens is relatively low, but the surface corrosion rate of the steel bars, the compressive strength of the concrete, and the corrosion resistance coefficient have all decreased to varying degrees, indicating that the specimens have begun to show damage.

\subsection{Analysis of Laboratory Test Results}

3.2.1. Appearance. The failure characteristics of a concrete specimen after 225 cycles of dry-wet-freeze-thaw cycles of composite salt are shown in Figure 13. It can be seen that the concrete at the corners degrades and small cracks appear around this area.

3.2.2. Quality. The change of mass loss rate of the pile foundation concrete specimens after 225 dry-wet-freezethaw cycles of the composite salts is shown in Figure 14(a). As the number of cycles increased, the mass loss rate of the specimen increased first and then stabilized. At 50 cycles, the 
TABLE 7: Corrosion rate of the steel bar area at different ages under different embedding conditions (\%).

\begin{tabular}{lcccccccccccc}
\hline \multirow{2}{*}{$\begin{array}{l}\text { Diameter of reinforcement } \\
\text { Time (d) }\end{array}$} & \multicolumn{4}{c}{1.25 m underground } & \multicolumn{2}{c}{1.25 m underground } & \multicolumn{3}{c}{ Surface } & \multicolumn{2}{c}{ Water } \\
\hline$\varphi 12$ & 90 & 270 & 360 & 90 & 270 & 360 & 90 & 270 & 360 & 90 & 270 & 360 \\
\hline$\varphi 25$ & 4.7 & 5.6 & 59 & 3.9 & 5.5 & 75 & 6.1 & 6.8 & 89 & 7.1 & 7.8 & 81 \\
\hline$\varphi 25^{\prime}$ & 4.6 & 5.3 & 65 & 3.9 & 5.2 & 66 & 5.8 & 6.5 & 91 & 7.5 & 7.4 & 76 \\
\hline
\end{tabular}

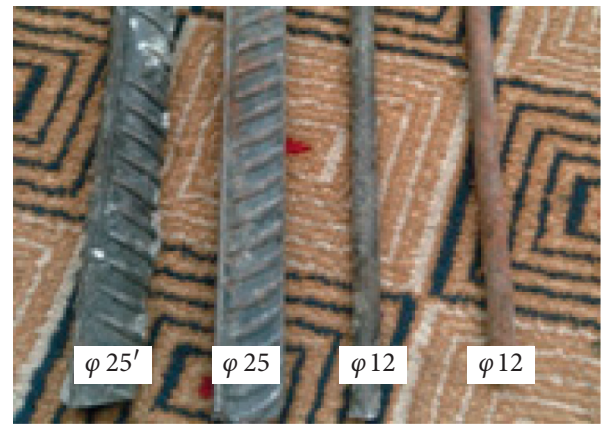

Figure 12: Rebar after removal.

TABLE 8: The corrosion rate of reinforced rebar.

\begin{tabular}{lccc}
\hline Rebar embedding position & Rebar diameter $(\mathrm{mm})$ & Area corrosion rate $(\%)$ & Mass loss rate $(\%)$ \\
\hline \multirow{3}{*}{ Surface } & 12 & 89 & 0.5 \\
& 25 & 91 & 0.5 \\
\hline \multirow{3}{*}{1.25 m underground } & $25^{\prime}$ & 59 & 0.2 \\
& 12 & 65 & 0.3 \\
& 25 & 2.6 & 0.3 \\
\hline
\end{tabular}

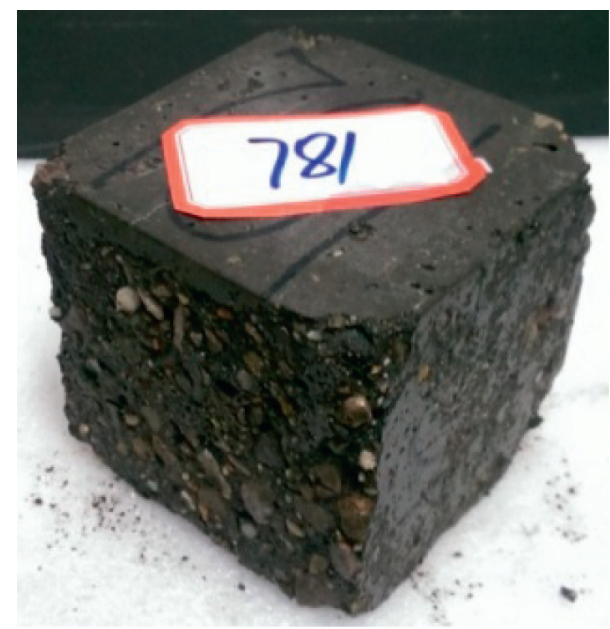

FIGURE 13: Failure characteristics of a concrete specimen.

mass loss rate was $1.04 \%$. After 225 cycles, the mass loss was $1.93 \%$, and the overall mass loss change was small.

3.2.3. Relative Dynamic Elastic Modulus. The sulfate and carbonate products produced by early corrosion increased the relative dynamic elastic modulus of the specimen (Figure 14(b)). As the number of cycles increased, the relative dynamic elastic modulus of the specimen decreased. After 225 cycles, the relative dynamic elastic modulus of the specimen decreased to $60.9 \%$, the specimen tended to break, and the pile foundation was considered insufficient.

3.2.4. Antierosion Coefficient. As the number of cycles increased, the antierosion coefficient of the specimen gradually decreased (Figure 14(c)). When the cycle was 0-50 times and 75-125 times, the decrease was 0.18 and 0.2. At 50-75 times, the decrease was 0.01 . The ettringite or calcite products generated by the corrosion at the beginning of the cycle made the soil around the pile body dense, and the change of the antierosion coefficient of the specimen slowed down. With the increase in the number of cycles, the tensile stress caused by the volume expansion of the corrosion products in the early stage was greater than the tensile stress of the specimen itself, and the cracks in the corrosion area of the specimen generated cracks, which reduced the strength. After 225 cycles, the antierosion coefficient decreased to 0.51 , and the damage was most extensive.

3.2.5. Compressive Strength. The compressive strength loss ratio of the specimen decreased, but the decline was small at first (Figure 14(d)). With the deterioration of specimen performance, the loss rate of compressive strength increased. 


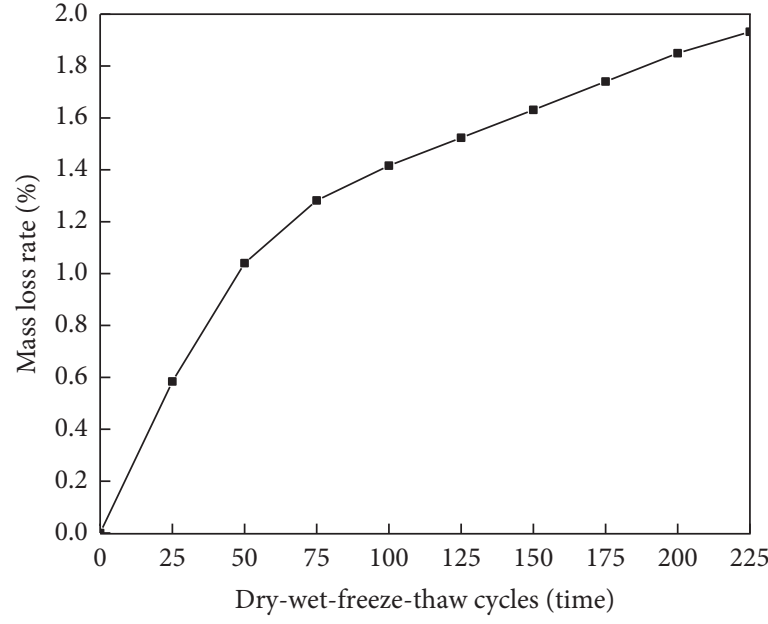

(a)

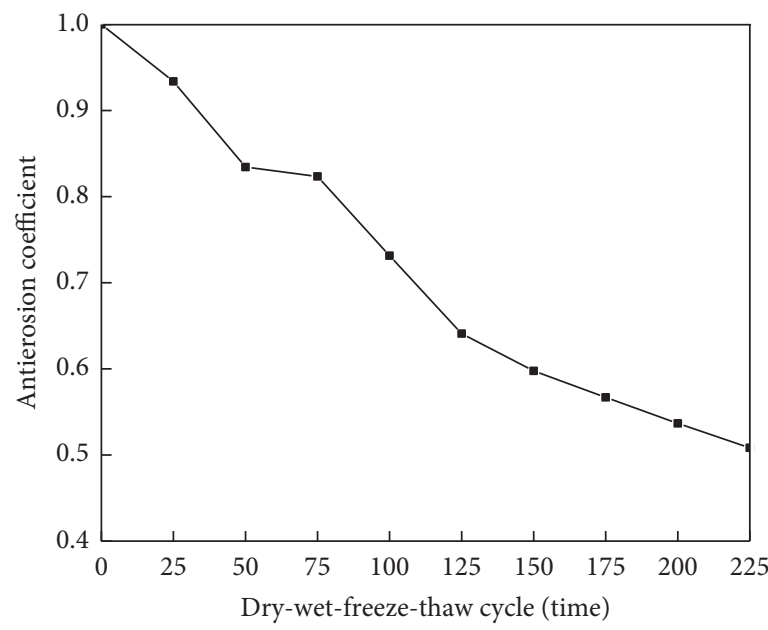

(c)

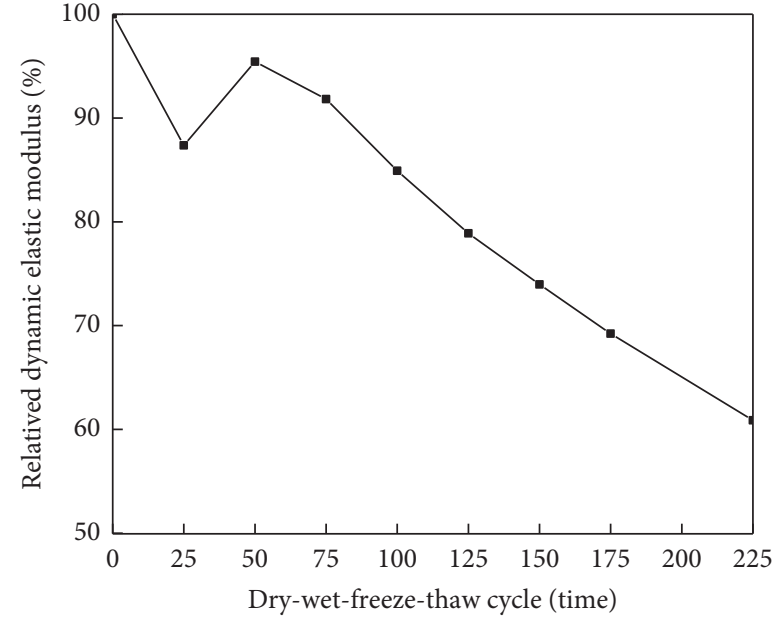

(b)

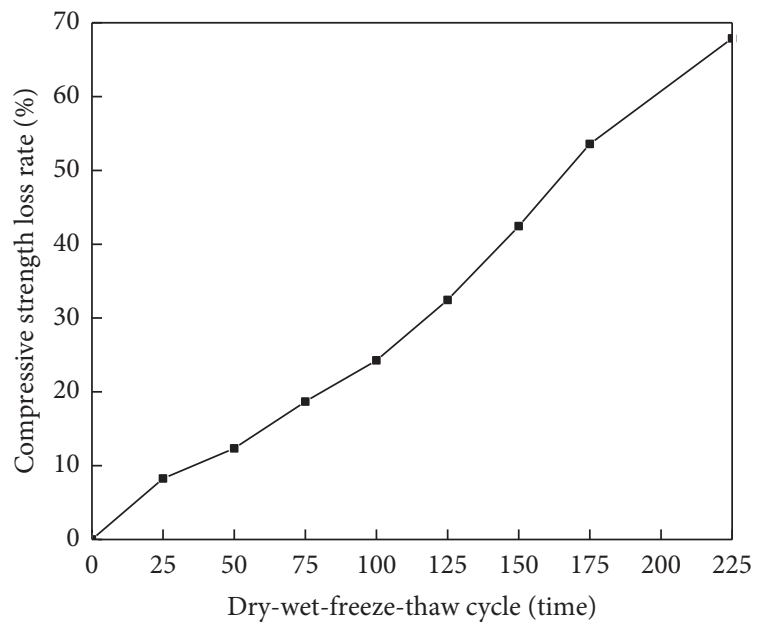

(d)

Figure 14: Variation of factors of concrete specimens for pile foundation tests. (a) Mass loss rate change. (b) Relative dynamic elastic modulus change. (c) Antierosion coefficient change. (d) Compressive strength loss rate.
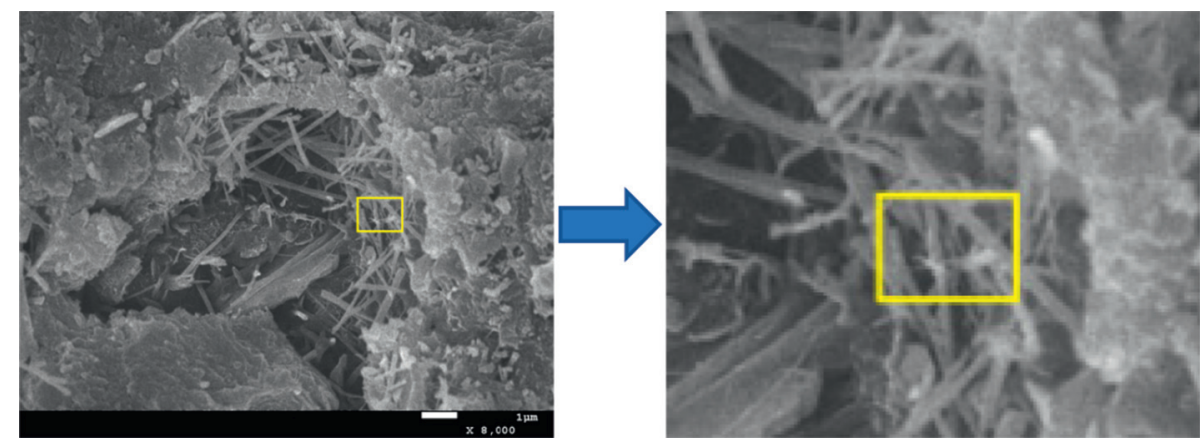

FIGURE 15: Microscopic SEM test chart of a pile foundation concrete specimen.

After 225 cycles, the loss rate of compressive strength was $65.9 \%$ and the damage was extensive.

3.2.6. Microscopic Mechanisms. A microscopic SEM image of the pile foundation concrete specimen after 225 cycles of dry-wet-freeze-thaw cycles with composite salt is shown in Figure 15. The EDS energy spectrum analysis is shown in Table 9. After 225 cycles, the specimen is loose, the amount of gelatinous substance is relatively low, and there is a large gap internally. In the EDS energy spectrum analysis, $\mathrm{C}, \mathrm{O}, \mathrm{Si}, \mathrm{Al}, \mathrm{Ca}$, and $\mathrm{Cl}$ were detected. This 
TABLE 9: EDS energy spectrum analysis of pile foundation concrete specimens in 225 dry-wet-freeze-thaw cycles.

\begin{tabular}{llll}
\hline & Element & Mole percent (\%) \\
\hline
\end{tabular}

suggests that after a long period of the dry-wet-freezethaw cycle, the strong penetrating $\mathrm{Cl}^{-}$enters the inside of the specimen. The specimen was damaged, but the intrusion of $\mathrm{Cl}^{-}$also inhibits the entry of $\mathrm{SO}_{4}{ }^{2-}$, resulting in a slower erosion. Since the presence of $S$ was not detected in the energy spectrum analysis, it indicated that the rodknitted fabric (yellow-framed) was not ettringite $\left(3 \mathrm{CaO} \cdot \mathrm{Al}_{2} \mathrm{O}_{3} \cdot 3 \mathrm{CaSO}_{4} \cdot 32 \mathrm{H}_{2} \mathrm{O}\right)$, but possibly Friedel salt $\left(3 \mathrm{CaO} \cdot \mathrm{Al}_{2} \mathrm{O}_{3} \cdot \mathrm{CaCl} \cdot 10 \mathrm{H}_{2} \mathrm{O}\right)$.

Limited by the in situ test conditions, the laboratory accelerated test is used to study the damage of concrete. The research results show that after 225 times of dry-wet-freezethaw cycles, the concrete specimens tend to be damaged, and the relative dynamic elastic modulus, corrosion resistance coefficient, and compressive strength of the specimens all show large damage changes. There is $\mathrm{cl}$ in the specimen, and Friedel salt may appear in the specimen. The appearance of concrete specimens showed partial peeling, and the quality of specimens changed relatively low.

3.3. Comparative Analysis of Indoor and In Situ Tests. After 1 year of in situ tests and 225 cycles of indoor dry-wetfreeze-thaw, the quality change of the pile foundation concrete specimen was shown to be similar, both less than $2 \%$. This indicated that the dry-wet-freeze-thaw cycle has little impact on the quality changes of specimens. After one year of in situ testing, the antierosion coefficient of pile foundation concrete specimens began to decrease, and the performance of the specimens began to deteriorate. The resulting regression equation had a good predictive ability of the antierosion coefficients. However, it is more difficult to predict the anticorrosion coefficient of specimens after many years, and the laboratory test was used to this end. After one year of in situ testing, the compressive strength loss rate of the concrete specimens of the pile foundation is similar to the results obtained from the laboratory test. With the increase of the number of dry-wet-freeze-thaw cycles and the interaction of various ions, the loss rate of compressive strength of the specimen obtained by the laboratory test generally increases.

3.4. Numerical Simulation Results. The change in the bearing capacity of the pile foundation in different years under different peeling thicknesses and corrosion depths is shown in Figure 16. The initial bearing capacity of the pile foundation is $587.51 \mathrm{kN}$. With the increase of the peeling thickness and the corrosion depth, the bearing capacity

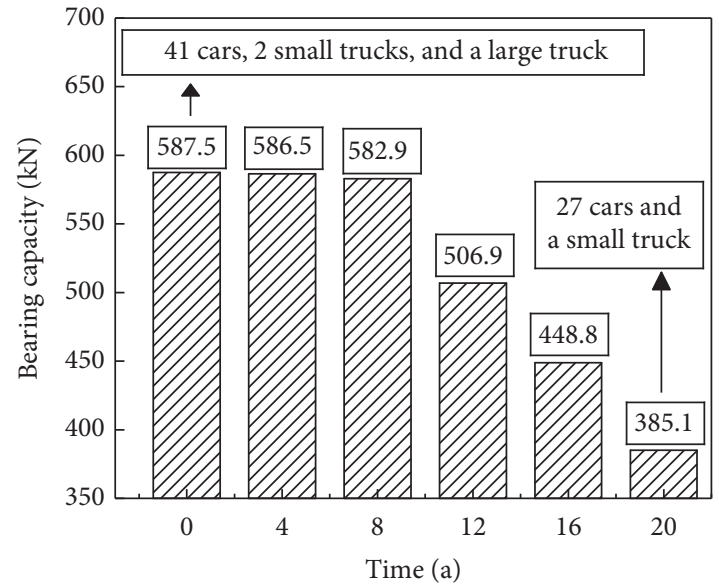

FIGURE 16: Change of the bearing capacity of different peeling thicknesses and corrosion depths in corresponding years.

decreases little in the first eight years, and the bearing capacity in the eighth year is $582.92 \mathrm{kN}$. After eight years, the bearing capacity gradually decreased. In the $20^{\text {th }}$ year, the bearing capacity is $385.12 \mathrm{kN}$, a decrease of $202.39 \mathrm{kN}$ which is $34.45 \%$. In the eighth year, the corresponding peeling thickness of the pile foundation was $6 \mathrm{~cm}$ and the corrosion depth was $3.2 \mathrm{~m}$. Therefore, it is believed that the pile foundation started to show damage around this time.

According to $[1,34]$, the weight of a personal car is 1 ton. The weight of a typical small truck is 5 tons and a large truck is 20 tons. According to previous research, during normal traffic, the ratios of the vehicles are 7 cars : 2 small trucks : 1 large truck. The initial bearing capacity of the pile foundation is $587.51 \mathrm{kN}$. At this time, it can bear 41 cars, 2 small trucks, and 1 large truck at the same time. After 8 years, the bearing capacity was reduced by $4.59 \mathrm{kN}$, which is equivalent to 0.5 cars. After 20 years, the bearing capacity is reduced by $202 \mathrm{kN}$, which is equivalent to 14 cars and a small truck.

Numerical simulation analysis believes that the bearing capacity of the pile foundation will be greatly reduced after 8 years. If no measures are taken, the operation of the pile foundation will be affected. In practice, it is suggested that an appropriate increase of pile diameter or pile length should be combined with long-term pile foundation protection measures to make up for the reduction of pile bearing capacity caused by pile corrosion, so as to ensure the safety of the highway bridge pile foundation during normal operation. 


\section{Conclusion}

(1) One year after the in situ test dry-wet-freeze-thaw cycle, the quality change of concrete specimen of the pile foundation is not obvious and the maximum loss rate of the compressive strength of it was $38.2 \%$. The change in the antierosion coefficient showed that the performance of the pile foundation began to deteriorate. The corrosion rate of rebar at a depth of $0.25 \mathrm{~m}$ was the largest, reaching $91 \%$. When the epoxy resin was applied on the surface of the rebar, the corrosion rate was significantly reduced.

(2) After 225 dry-wet-freeze-thaw cycles (representing about 20 years) in the laboratory test, the corner of the concrete specimen of the pile foundation deteriorated. The quality change of pile foundation concrete specimen is not obvious. The antierosion coefficient gradually decreases to 0.51 and the damage is serious. The relative dynamic elastic modulus was reduced by $39.1 \%$. The compressive strength loss rate was $65.9 \%$. Due to expansive substances, such as Friedel salt, the concrete tended to deteriorate. It is suggested that construction should be completed three months before the freezing period, and unscheduled maintenance and repair be carried out according to the conditions of a given situation.

(3) The bearing capacity of the pile foundation remained unchanged for the first eight years of the wet-dryfreeze-thaw cycle and gradually decreased after eight years, with a decrease of $34.45 \%$ in the $20^{\text {th }}$ year. In later periods of service, attention should be paid to pile foundation protection. In construction, a steel casing can be used to protect the bridge pile foundation.

(4) Due to the limitation of in situ test conditions, this paper uses laboratory test and numerical simulation methods on the basis of in situ tests to study the corrosion damage and bearing characteristics of bridge pile foundations under dry-wet-freeze-thaw cycles in the alpine salt marsh area. The similar complex multifactor coupling and special conditions of bridge pile foundation research provide reference and have very important guiding significance.

\section{Data Availability}

The data used to support the findings of this study are available from the corresponding author upon request.

\section{Conflicts of Interest}

The authors declare no conflicts of interest.

\section{Acknowledgments}

This research was funded by the National key Research and Development Program of China (no. 2018YFC1504801); Traffic Science and Technology Projects in Guangdong Province (2013-02-010 and 2011-01-001); Key Transportation Science and Technology Research Projects in
Qinghai Province (2014-07); and Traffic Science and Technology Projects in Hainan Province (HNZXY2015045R).

\section{References}

[1] Z. Feng, H. Hu, Y. Dong et al., "Effect of steel casing on vertical bearing characteristics of steel tube-reinforced concrete piles in loess area," Applied Sciences, vol. 9, no. 14, p. 2874, 2019.

[2] Z. J. Feng, J. W. Huo, and H. B. Hu, "Corrosion damage and bearing characteristics of bridge pile foundations under drywet-freeze-thaw cycle in alpine salt marsh area," Journal of Traffic and Transportation Engineering, vol. 20, no. 6, pp. 1-14, 2020.

[3] Z. J. Feng, H. B. Hu, and F. C. Wang, "Field simulation test of bridge pile foundation damage in high altitude and strong salt marsh area," Journal of Traffic and Transportation Engineering, vol. 19, no. 3, pp. 46-57, 2019.

[4] A. Neville, "Consideration of durability of concrete structures: past, present, and future," Materials and Structures, vol. 34, no. 2, pp. 114-118, 2001.

[5] Z. Meng, Z. Yang, Z. Yin et al., "Effects of coal slime on the slurry ability of a semi-coke water slurry," Powder Technology, vol. 359, pp. 261-267, 2020.

[6] A. F. Murad, X. B. Yu, and P. Binay, "Field testing and analyses of a batter pile group foundation under lateral loading," Transportation Research Record: Journal of the Transportation Research Board, vol. 2212, no. 1, 2011.

[7] B. Pathak, M. . Abu-Farsakh, X. Yu, and K. Alshibli, "Interpretation of lateral load test of batter pile group using highorder polynomials curve fitting," Advances in Geotechnical Engineering, vol. 2011, pp. 152-161, 2011.

[8] S. Pilehvar, A. M. Szczotok, J. F. Rodríguez et al., "Effect of freeze-thaw cycles on the mechanical behavior of geopolymer concrete and Portland cement concrete containing microencapsulated phase change materials," Construction and Building Materials, vol. 200, no. 10, pp. 94-103, 2019.

[9] H. Yazıc1, "The effect of silica fume and high-volume class C fly ash on mechanical properties, chloride penetration and freeze-thaw resistance of self-compacting concrete," Construction \& Building Materials, vol. 22, no. 4, pp. 456-462, 2008.

[10] Z. Feng, H. Hu, R. Zhao et al., "Experiments on reducing negative skin friction of piles," Advances in Civil Engineering, vol. 2019, Article ID 4201842, 10 pages, 2019.

[11] R. Slavik, V. Bednarik, M. Vondruska, and A. Nemec, "Preparation of geopolymer from fluidized bed combustion bottom ash," Journal of Materials Processing Technology, vol. 200, no. 1-3, pp. 265-270, 2008.

[12] A. Ghazy and M. T. Bassuoni, "Response of concrete with blended binders and nanosilica to alternating wet-dry and freeze-thaw cycles with chloride-based salts," Magazine of Concrete Research, vol. 2018, pp. 1-44, 2018.

[13] A. Allahverdi, M. M. B. R. Abadi, K. M. Anwar Hossain, and M. Lachemi, "Resistance of chemically-activated high phosphorous slag content cement against freeze-thaw cycles," Cold Regions Science and Technology, vol. 103, no. 7, pp. 107-114, 2014.

[14] G. Al-Assadi, M. J. Casati, and J. Fernandez, "Effect of the curing conditions of concrete on the behaviour under freezethaw cycles," Fatigue \& Fracture of Engineering Materials \& Structures, vol. 34, no. 7, 2011. 
[15] X. Y. Shi, Z. Zhang, and D. Q. Li, "Research on dynamic variation of moisture, temperature and deformation of conecylindrical pile under freeze-thaw cycles," Journal of Rock Mechanics and Engineering, vol. 38, pp. 3092-3101, 2019.

[16] M. H. E. Naggar and M. Sakr, "Evaluation of axial performance of tapered piles from centrifuge tests," Canadian Geotechnical Journal, vol. 37, no. 6, pp. 1295-1308, 2000.

[17] Y. Dong, Z. Feng, H. Hu, J. He, Q. Zhang, and F. Wang, “The horizontal bearing capacity of composite concrete-filled steel tube piles," Advances in Civil Engineering, vol. 2020, Article ID 3241602, 15 pages, 2020.

[18] Y. Dong, Z. Feng, J. He, H. Chen, G. Jiang, and H. Yin, "Seismic response of a bridge pile foundation during a shaking table test," Shock and Vibration, vol. 2019, Article ID 9726013, 16 pages, 2019.

[19] E. M. Ali and S. E. M. Abbadi, "A technical note on the probabilistic analysis of short piles on expansive soil," Civil Engineering Systems, vol. 5, no. 3, pp. 159-163, 1988.

[20] C. Ferregut and M. Picornell, "Reliability analysis of drilled piers in expansive soils," Canadian Geotechnical Journal, vol. 28, no. 6, pp. 834-842, 1991.

[21] K. Yan, J. He, Q. Cheng, G. Fan, Z. Wang, and J. Zhang, “A centrifugal experimental investigation on the seismic response of group-pile foundation in a slope with an inclined weak intercalated layer," Soil Dynamics and Earthquake Engineering, vol. 130, Article ID 105961, 2020.

[22] Z. J. Feng, H. Y. Chen, and F. B. Yuan, "Vertical bearing characteristics of bridge pile foundation under coupling of pile-soil-fault," Journal of Traffic and Transportation Engineering, vol. 19, no. 2, pp. 36-48, 2019.

[23] X. H. Yao, Z. J. Feng, and F. C. Wang, "Property of multiple admixture-concrete in multi-salt soaking under wettingdrying and freezing-thaw cycles," Acta Composites, vol. 35, no. 3, pp. 690-698, 2018.

[24] Z. J. Feng, S. X. Chen, and H. Xu, "Evaluation of concrete durability in alpine salt marshes based on grey system theory," Journal of Traffic and Transportation Engineering, vol. 18, no. 6, pp. 18-26, 2018.

[25] R. E. Weyers, "Service life model for concrete structures in chloride laden environments," ACI Materials Journal, vol. 95, no. 4, pp. 445-453, 1998.

[26] R. Lang, R. Liu, J. Lian, and H. Ding, "Study on load-bearing characteristics of different types of pile group foundations for an offshore wind turbine," Journal of Coastal Research, vol. 73, pp. 533-541, 2015.

[27] D. B. Ribeiro and J. B. de Paiva, "A new BE formulation coupled to the FEM for simulating vertical pile groups," Engineering Analysis with Boundary Elements, vol. 41, pp. 1-9, 2014.

[28] Z. J. Feng, X. Q. Wang, and X. X. Li, "The influence of sand liquefaction under strong earthquake on the mechanical properties of pile foundation," Journal of Traffic and Transportation Engineering, vol. 19, no. 1, pp. 71-84, 2019.

[29] Z. J. Kuang, Research on Traffic Safety Assessment and Countermeasures of Nandan Expressway of Lanhai, Tsinghua University, Beijing, China, 2017.

[30] X. D. Ou, Y. C. Tang, and W. Cui, "Model test and numerical simulation of h-type anti-slide pile," Journal of Rock Mechanics and Engineering, vol. 31, no. 9, pp. 1936-1943, 2012.

[31] Y. Xiao, M. H. Zhao, and R. Zhang, "Finite element limit analysis of bridge double pile foundation in Karst area," Journal of Engineering Geology, vol. 27, no. 4, pp. 923-932, 2019.
[32] H. R. Wu, W. L. Jin, and Y. D. Yan, "Regionalization of freezing and thawing environment of concrete and prediction of freezing resistance life," Journal of Zhejiang University (Engineering Science), vol. 46, no. 4, pp. 650-657, 2012.

[33] J. B. Wang, Y. T. Niu, and H. He, "Durability of sprayed concrete under the action of nitric acid erosion/freeze-thaw cycle (II) $-\mathrm{pH}$ value and $\mathrm{NO}_{3}$-diffusion," Journal of Civil Engineering, vol. 52, no. 7, pp. 1-12, 2019.

[34] K. R. Prasanna and M. Hemalatha, "RFID GPS and GSM based logistics vehicle load balancing and tracking mechanism," Procedia Engineering, vol. 30, no. 4, pp. 726-729, 2012. 